\title{
High community turnover and dispersal limitation relative to rapid climate change
}

\author{
Authors: Jayme M. M. Lewthwaite, Diane M. \\ Debinski, and Jeremy T. Kerr
}

This is the peer reviewed version of the following article: [Lewthwaite, Jayme M. M., Debinski, Diane M., \& Kerr, Jeremy T. (2016). High community turnover and dispersal limitation relative to rapid climate change. Global Ecology and Biogeography 26(4), 459-471.], which has been published in final form at http://dx.doi.org/10.1111/geb.12553. This article may be used for noncommercial purposes in accordance with Wiley Terms and Conditions for Self-Archiving.

Lewthwaite, Jayme M. M., Debinski, Diane M., \& Kerr, Jeremy T. (2016). High community turnover and dispersal limitation relative to rapid climate change. Global Ecology and Biogeography, 26(4), 459-471. doi:10.1111/geb.12553

Made available through Montana State University's ScholarWorks scholarworks.montana.edu 


\title{
High community turnover and dispersal limitation relative to rapid climate change
}

\author{
Jayme M. M. Lewthwaite ${ }^{1 \star}$, Diane M. Debinski ${ }^{3}$ and Jeremy T. Kerr ${ }^{2}$ \\ ${ }^{1}$ Department of Biological Sciences, Simon \\ Fraser University, Burnaby, BC Canada V5A \\ 1S6, ${ }^{2}$ Department of Biology, University of \\ Ottawa, Ottawa, ON Canada K1N 6N5, \\ ${ }^{3}$ Department of Ecology, Evolution and \\ Organismal Biology, Iowa State University, \\ Ames, IA 50010, USA
}

\begin{abstract}
Aim Many competing hypotheses seek to identify the mechanisms behind species richness gradients. Yet, the determinants of species turnover over broad scales are uncertain. We test whether environmental dissimilarity predicts biotic turnover spatially and temporally across an array of environmental variables and spatial scales using recently observed climate changes as a pseudoexperimental opportunity.

Location Canada.

Methods We used an extensive database of observation records of 282 Canadian butterfly species collected between 1900 and 2010 to characterize spatial and temporal turnover based on Jaccard indices. We compare relationships between spatial turnover and differences in an array of relevant environmental conditions, including aspects of temperature, precipitation, elevation, primary productivity and land cover. Measurements were taken within 100-, 200- and 400-km grid cells, respectively. We tested the relative importance of each variable in predicting spatial turnover using bootstrap analysis. Finally, we tested for effects of temperature and precipitation change on temporal turnover, including distinctly accounting for turnover under individual species' potential dispersal limitations.

Results Temperature differences between areas correlate with spatial turnover in butterfly assemblages, independently of distance, sampling differences or the spatial resolution of the analysis. Increasing temperatures are positively related to biotic turnover within quadrats through time. Limitations on species dispersal may cause observed biotic turnover to be lower than expected given the magnitude of temperature changes through time.

Main conclusions Temperature differences can account for spatial trends in biotic dissimilarity and turnover through time in areas where climate is changing. Butterfly communities are changing quickly in some areas, probably reflecting the dispersal capacities of individual species. However, turnover is lower through time than expected in many areas, suggesting that further work is needed to understand the factors that limit dispersal across broad regions. Our results illustrate the large-scale effects of climate change on biodiversity in areas with strong environmental gradients.
\end{abstract}

\section{Keywords}

Beta diversity, Canada, climate change, community composition, conservation, dispersal, macroecology, species turnover, temperature.

${ }^{\star}$ Correspondence: Jayme M. M. Lewthwaite, Department of Biological Sciences, Simon Fraser University, Burnaby, BC, Canada V5A 1 S6.

E-mail: jlewthwa@sfu.ca 


\section{INTRODUCTION}

Broad-scale variation in species richness reflects environmental differences that might also drive species turnover between regions (Kerr et al., 2001). As environmental conditions change across spatial gradients or through time, species composition also changes (Whittaker, 1972; Legendre \& De Cáceres, 2013). While the leading environmental correlates of species richness are known (Field et al., 2009), whether such factors contribute to species turnover between regions is far less well known (Chase \& Myers, 2011; Qian \& Ricklefs, 2012). Stronger tests relating temporal species turnover to observed environmental change have rarely been possible, given data limitations.

Much of the complexity involved in detangling the spatial patterns of species turnover lies in the variety of factors that can obscure results. Firstly, the number of species detected at regional extents can affect biotic turnover and increase uncertainties around the apparent importance of processes that shape turnover (Kraft et al., 2011). Secondly, environmental differences in factors such as primary productivity (Andrew et al., 2012) and habitat heterogeneity (Meynard et al., 2011) affect community assembly, and may do so differently at local and regional extents; this may consequently also influence comparisons of turnover between sites. Furthermore, species traits, particularly dispersal ability (Dobrovolski et al., 2012), also determine whether species are present in regional species pools from which local biological communities are drawn (Leroux et al., 2013). Regions can also have locally unique histories that may alter species presences, and consequently also patterns of turnover, relative to other areas, adding complexity to comparisons between areas (Ulrich \& Gotelli, 2014). Finally, many metrics exist to describe biotic turnover (Koleff et al., 2003) and potentially account for additional factors, such as gradients in alpha diversity (Jurasinski et al., 2009).

Although many environmental variables have been linked with biotic turnover, climate has emerged as a particularly important predictor of species turnover through space (Hillebrand et al., 2010; Pellissier et al., 2013). Temperature can impose physiological constraints on species (Boucher-Lalonde et al., 2012), contributing to local climatic adaptation within a species. Consequently, climatic tolerance influences species' geographical ranges (Kerr et al., 2015). Regional species composition is then a function of the numbers of species drawn from the continental pool that have overlapping climatic tolerances (Algar et al., 2011). Thus, spatial variation in climate between regions should contribute to differences in community composition (Veech \& Crist, 2007; Keil et al., 2012). While proving causation in the context of correlation is practically impossible, the likelihood that such relationships reflect causal processes rises if spatial relationships change through time in directions predicted from those spatial relationships (Kerr et al., 2007; Blois et al., 2013; Eskildsen et al., 2013). Global change presents a unique opportunity to greatly strengthen tests of existing biotic hypotheses based on spatial correlation (Kerr et al., 2007; Algar et al., 2009; Kharouba et al., 2009), and to evaluate the performance of space for time substitution models, in which spatial relationships are used to predict temporal responses (Elith \& Leathwick, 2009; Blois et al., 2013).

Although space for time substitutions perform especially well with community data (Blois et al., 2013), several processes - both biotic and abiotic - could obscure trends in species turnover through time. Species-specific traits, such as dispersal capacity or interspecific competition, could reduce the likelihood that a species could establish or maintain populations in an area (Ferrier \& Guisan, 2006; Tylianakis et al., 2008; Wiens et al., 2009). Environmental changes can also alter patterns of niche occupancy among species (Veloz et al., 2012). For example, species turnover may change erratically because geographical range shifts among species may track tolerances weakly or only in some areas. Importantly, climate change is accompanied by an increasing frequency and intensity of extreme events, which also complicate predictions of biotic responses through time (Jackson et al., 2009). However, it is imperative that we first analyse the extent of the relationship between environmental dissimilarity and both spatial and temporal species turnover in order to make subsequent improvements in applying a space for time analysis.

Another complication with evaluating species turnover is the diversity of measurement methods in the literature, which can make comparisons across studies challenging (Soininen, 2010). However, recent analyses suggest that metrics such as the Jaccard index are effective tools for investigating the determinants of turnover (Legendre \& De Cáceres, 2013). The scale of analysis can further complicate comparisons, as it can yield different outcomes at different spatial grains (Lennon et al., 2001). Thus, examination of the variation in biotic turnover across several spatial scales can help distinguish the relative importance of processes at each scale (Chalcraft et al., 2004; Kraft et al., 2011). Extending these analyses to broader geographical areas (Blackburn \& Gaston, 1996; Gaston et al., 2007) and comparing diverse groups of organisms (Buckley \& Jetz, 2008) will also help to overcome local-level contingencies.

Although species turnover is related to a number of environmental factors (Soininen, 2010), their relative importance remains unclear (Stegen et al., 2013). Accounting for distance (Nekola \& White, 1999) enables the potential role that environmental differences may have in species turnover between areas to be tested (Tuomisto \& Ruokolainen, 2006). This approach has been used successfully to examine turnover across geographical (McKnight et al., 2007) and environmental space (Qian \& Ricklefs, 2007, 2012; Buckley \& Jetz, 2008).

Here, we examine an array of factors that could explain species turnover and compare their relative capacities to predict species turnover among Canadian butterflies. We repeated analyses at three scales $(100 \mathrm{~km} \times 100 \mathrm{~km}, 200 \mathrm{~km}$ $\times 200 \mathrm{~km}$ and $400 \mathrm{~km} \times 400 \mathrm{~km}$ ) across Canada (c. $9.9 \times$ $10^{6} \mathrm{~km}^{2}$ ). We then tested whether these relationships remained consistent as environmental (and particularly 
climatic) conditions changed. We partitioned trends in turnover between spatial and environmental components and accounted for potential dispersal limitations among species. To our knowledge, this is the first study to examine changes in both spatial and temporal community composition in this region. Rapid climate changes create pseudo-experimental opportunities to test spatial relationships (e.g. Kerr et al., 2007).

\section{METHODS}

\section{Butterfly data}

Butterfly records were obtained from a combination of sources: the Canadian Biodiversity Information Facility (CBIF), the Toronto Entomological Association, e-Butterfly.org (Larrivée et al., 2014), museum collections and many lepidopterists' personal collections. Altogether, there are $c$. 300,000 georeferenced and temporally dated records for 307 species, the majority of which are traceable to a curated museum specimen. Most records have been dated and georeferenced to within a positional accuracy of $<10 \mathrm{~km}$.

Climate changes accelerated greatly across this region after about 1975 (Parmesan, 2006). For that reason, we divided records into baseline $(1900-74, n=38,306)$ and recent $(1985-2010, n=127,906)$ sets; there was a total of 282 species within the quadrats selected for our study area (see below). For the spatial component of the analyses, we considered only the 38,306 records from 1900 to 1974 to capture the species composition prior to most anthropogenic climate change. For temporal analyses, we compared the two time periods to measure community turnover. The temporal distribution of records within Canada is given in Fig. S1 in the Supporting Information.

\section{Quadrat system}

A map of the geopolitical boundaries of Canada was reprojected into the Albers' equal area projection to conserve area. Using ArcGIS 10.3 (ArcGIS Desktop, 2014), we divided the study region into hierarchical grid systems, with cell sizes of $100 \mathrm{~km} \times 100 \mathrm{~km}, 200 \mathrm{~km} \times 200 \mathrm{~km}$ and $400 \mathrm{~km} \times$ $400 \mathrm{~km}$, respectively. We excluded all unsampled quadrats from the spatial analysis and those not sampled in both time periods from the temporal analysis. The distances from the centroid of each quadrat to all of the corresponding quadrats were measured using the 'Point Distance' tool in ArcGIS. For each time period (1900-74 and 1985-2010) we assessed the species composition within each quadrat, which was used as the input variable to measure spatial and temporal turnover.

\section{Environmental indices}

Annual measurements of temperature (maximum, minimum and average) and total annual precipitation were obtained through the Canadian Forest Service at $10-\mathrm{km}$ resolution (McKenney et al., 2011). These data are based on the complete collection of meteorological data for Canada from 1901 to 2010 and were developed using ANUSPLIN (see McKenney et al., 2011). WorldClim was used to obtain elevation measurements and NDVI data were measured using AVHRR (the Advanced Very High Resolution Radiometer) satellite imagery at $8-\mathrm{km}$ resolution. AVHRR composites for Canada are available as of 1981 from the Global Land Cover Facility at the University of Maryland (http://glcf.umd.edu). This is the only remote sensing platform that is capable of providing long-term, synoptic measurements across the whole of Canada's landmass and is uniquely valuable for temporal analysis at macroecological extents (Kerr \& Ostrovsky, 2003). AVHRR data were composited over a 15-day period to yield a direct observation of peak greenness for all of Canada's terrestrial landmass (Pinzon \& Tucker, 2014). We used the earliest available imagery for NDVI (averaged over July observations from 1981-84) to represent the baseline time period. There is a temporal discrepancy between the NDVI measure and our spatial analysis of turnover because our baseline time period spans the period 1900-74. We assume that 1981-84 measurements reasonably represent the spatial variation in NDVI in the baseline time period. NDVI can change substantially and rapidly in response to climate change (Myneni et al., 1997, Goetz et al., 2005) and could contribute to shifts in butterfly community structure between the baseline and recent time periods.

The normalized difference vegetation index (NDVI) relates strongly to net primary productivity across Canada, where leaf area indices are sufficiently low that the NDVI does not saturate (Liu et al., 1997; Evans et al., 2006). NDVI has been widely used in the literature to assess vegetative responses to climate change and monitor habitat loss and fragmentation (Kerr \& Ostrovsky, 2003; Chen et al., 2005; Pettorelli, 2013). As with all environmental observations (including interpolated climatic data that are used ubiquitously in macroecological and other research), there are weaknesses in remote sensing measurements that need to be recognized (Pettorelli et al., 2005). NDVI measurements may be misleading in regions with persistently high humidity and cloud cover, in regions with especially dense vegetation or where there is a lack of vegetation cover (Goward et al., 1991). Our study focuses on broad scales and relative differences in peak (summer) NDVI values in vegetated areas and at spatial and temporal scales at which NDVI is robust.

Validated land-use and land-cover data were obtained from Kerr \& Cihlar (2003). These data include 59 classes, 14 of which represent agricultural land uses and were derived from processed SPOT 4/VEGETATION (VGT) observations (for a full description of methods see Kerr \& Cihlar, 2003). These data depict the array of agricultural land uses across Canada. Areas beyond agricultural and human-dominated landscapes were measured using validated national landcover data for Canada (Cihlar et al., 2001). The integrated land-use/land-cover dataset incorporated a census of agriculture observations that was obtained through exhaustive survey of agricultural producers across Canada (Statistics 
Canada, 1996). Details on this land-use classification are given in Table S1.

Mean values (for continuous measures, such as minimum, maximum and average temperature, precipitation, elevation and NDVI) or diversity measures (for categorical variables, such as land use/land cover) from 1900 to 1974 were extracted for each quadrat using ArcGIS. The exceptions include NDVI, which was averaged over 1981-84, elevation (which is temporally invariant) and land use/land cover where only one measurement through time is currently available. This was repeated at each scale of analysis $(100 \mathrm{~km} \times$ $100 \mathrm{~km}, 200 \mathrm{~km} \times 200 \mathrm{~km}$ and $400 \mathrm{~km} \times 400 \mathrm{~km}$ quadrats).

A scatterplot matrix of all eight environmental variables was constructed using $\mathrm{R}$ to explore multicollinearity among predictors. From these scatterplots, it was evident that temperature measures were highly correlated. However, there was no significant correlation between any of the remaining environmental measures. Therefore, a single synthetic measure of temperature was created from these measures using principal components analysis (PCA), and the first principal component in subsequent multivariate spatial and temporal analyses. The PCA was conducted using the stats package in R ( $\mathrm{R}$ Development Core Team, 2013).

For the temporal analysis, the synthetic temperature measurement was extracted for each year and divided into two time periods (1900-74 and 1985-2010). Environmental measures, including precipitation, NDVI and the principal component of the temperature variables, were taken as means across each quadrat for each time period. Absolute values of change in precipitation and NDVI were then calculated. A gap period of 10 years was incorporated in order to allow potential species responses to changing environmental conditions.

\section{Sampling intensity}

There was a large amount of variation in where and when butterfly records were collected. To account for the possible effect of sampling intensity, we included two measures of sampling intensity between 1900 and 1974 in our spatial analysis. The first is average sampling intensity, which was the average number of records collected per year in a quadrat. The second was absolute sampling intensity, which was simply the total number of records collected in a quadrat across 1900-74. Although the two metrics show some correlation, we included both of them to account for temporal inconsistency in sampling between quadrats (for example, some quadrats were sampled intensively but only in certain years, whereas other quadrats have a lower number of total records but have been sampled more consistently throughout the years). For our temporal analysis, we compared the difference in the total number of observation records between 1900-74 and 1985-2010 to examine if this had any effect on our temporal turnover scores. There were three outlier points; we conducted the test with and without them in order to ensure that they did not influence the results.

\section{Spatial and temporal analyses}

The R package vegan (Oksanen et al., 2015) was used to calculate beta diversity between quadrats, using the Jaccard index of dissimilarity. This index ranges from zero to one, the higher values indicating a more dissimilar community:

$B_{j}=1-\frac{a}{a+b+c}$

where $b$ and $c$ represent the number of species unique to site 1 and 2, respectively, and $a$ represents the number of species they have in common.

Standard dissimilarity metrics can conflate nestedness and turnover (Baselga et al., 2007). However, the pairwise Simpson dissimilarity measure has been used in the literature as an effective means of differentiating between the two. Thus, in a separate analysis, we partitioned our beta-diversity measurement into both a turnover and nestedness component using Simpson's dissimilarity measure and the approach and R scripts outlined in Baselga (2010).

Spatial analysis

For the first portion of the analysis, the vegan package in $\mathrm{R}$ 3.1 (R Development Core Team, 2013) was used to calculate a pairwise environmental matrix between each quadrat and all others in the analysis. Thus, for each variable (distance, temperature, precipitation, elevation, NDVI, land cover), the environmental distance is calculated between the average quadrat values. Land use/land cover is a categorical variable, and we first calculated the total variety of land-cover types within a grid cell (this value could range from a single land-cover type to 59 different land-cover types within a grid cell). Then, we compared the difference between grid cells by calculating the Euclidean distance in the proportion of land-cover types by which they differed (so a high distance represents few landcover types in common between grid cells). We explored relationships among predictor variables and pairwise Jaccard distance measures by plotting each as a bivariate relationship. While macroecological analyses routinely account for spatial autocorrelation (Dormann et al., 2007), conventional approaches to address that issue cannot be used on community distance measures that do not have unique spatial coordinates. Instead, we measured the geographical distance between all quadrats for which Jaccard distances were calculated; this measure was included in regression models to account for the likelihood that distance would affect community similarity. Relationships were plotted using hexagonal density plots with the hexbin package (Carr, 2014). To avoid redundancy and to save valuable space within the manuscript, only the results for geographical distance, average temperature and NDVI are included within the main paper (the remainder are included in the Supporting Information). We chose these three variables as they are among the most widely researched correlates of 
turnover in the literature and considered to be some of the best predictors (see Veech \& Crist 2007; Andrew et al., 2012; Keil et al., 2012).

We then performed a multivariate linear regression of spatial turnover (measured as the Jaccard index of dissimilarity) as a function of environmental distance for each of the three quadrat sizes. Independent environmental distance variables included difference in temperature (the first principal component of mean, minimum and maximum temperaturediscussed above), precipitation, elevation, NDVI and land use/land cover. We also included a variable that accounted for geographical distance between quadrats, as well as two sampling intensity variables (absolute sampling intensity per quadrat and mean yearly sampling intensity per quadrat). A histogram of the residuals suggested that assumptions of normality and homoscedasticity were met (see Figs S2 \& S3 for example diagnostic plots of the residuals for the $400 \mathrm{~km} \times$ $400 \mathrm{~km}$ scale).

From the multiple regression, we performed a bootstrap analysis (1000 permutations) to test variable importance using four methods found within the package relaimpo (Grömping, 2006). The first (labelled 'LMG' in Fig. 2) represents the contribution to the coefficient of determination among regressors, averaged over different orderings (i.e. Lindeman, Merenda and Gold; see Lindeman et al., 1980). 'Last' details each variable's contribution when included last in the model (sometimes called 'usefulness'; Darlington, 1968). 'First' represents the contribution of each variable when included first (simply, the squared covariance between the response and predictors). Finally, 'Pratt' calculates the product of the standardized coefficient and the correlation (Pratt, 1987). We reran this analysis with the Simpson dissimilarity measure to ensure that the results were consistent between metrics.

\section{Temporal analysis}

The difference in species compositions within each quadrat over two time periods was calculated using the Jaccard index of dissimilarity in R. The difference in mean temperature as well as the absolute differences in total precipitation and NDVI between the two time periods was calculated for each quadrat. Community dissimilarity was then graphed as a function of the change in the environmental variable between time periods. Finally, a linear regression was performed to test whether change in temperature, NDVI or precipitation were correlated with species turnover. We also tested whether the inclusion of several sampling intensity variables (difference in sampling intensity between time periods, absolute sampling intensity in Time 1, absolute sampling intensity in Time 2) affected model results.

\section{Dispersal-limited analysis}

We were interested to see whether dispersal limitations may be limiting the rate at which species keep pace with temperature change. Consequently, we predicted that observed turnover rates would be lower than expected when compared with the turnover levels anticipated if species are indeed moving freely. Maximum dispersal limitations in response to climate change within this insect group have previously been found to be approximately $10 \mathrm{~km}$ year ${ }^{-1}$ (Chen et al., 2011). To test whether species turnover values in a quadrat could be linked to the dispersal limitations of this group, we generated expected turnover rates for each quadrat in the second time period (1985-2010) if a species' dispersal was limited to $100 \mathrm{~km}$ from its original location in 1900-74. To do this, we added a $100-\mathrm{km}$ circular buffer around each individual's preclimate-change record (1900-74) to represent the areas to which a species could disperse over the 10-year gap separating the two study periods. Species were thus counted as present in all adjacent quadrats into which their maximum buffer zone extended. This became the predicted Time 2 map of presence/absences. We recalculated temporal turnover rates within a quadrat by measuring the difference in communities between the observed Time 1 records and the new Time 2 predicted presence/absence matrix generated by the buffered records, which was the expected turnover rate accounting for dispersal limitation. We compared the results with observed temporal turnover rates (which used only true observation records) to evaluate whether dispersal limitation was likely to alter measured turnover trends.

This analysis layers in the additional factor that species cannot move unlimited distances over the time separating the two study periods (1901-74 and 1985-2010). The form of dispersal limitation we have included here is effectively a kind of neutral model in which species diffuse outward from places where they were historically known to occur. We compare that against predictions from the environmental model.

\section{RESULTS}

Mean temperature difference between quadrats was the best predictor of spatial turnover (measured as the Jaccard index of dissimilarity) at all three scales (Fig. 1). The finest-scale analysis of the differences in mean temperature $(100 \mathrm{~km} \times$ $100 \mathrm{~km}$ ) explained the highest proportion of variance (coefficient $\left.=0.030, \quad R^{2}=0.6149\right) \quad$ compared with broader-scale assessments $\left(R^{2}=0.5752\right.$ for $200 \mathrm{~km} \times 200 \mathrm{~km} ; R^{2}=0.5529$ for $400 \mathrm{~km} \times 400 \mathrm{~km}$ ). Importantly, for the individual linear regressions, a much larger proportion of variance was explained by each of the three individual temperature variables (mean, minimum and maximum temperature) than by distance between quadrats (see Figs $1 \&$ S4). Some environmental variables performed better at the smallest scale (mean temperature, minimum temperature, precipitation; see Figs 1 \& S4), whereas others accounted for more variance at the largest scale measured (distance, maximum temperature, elevation, NDVI and land-use/land-cover change; see Figs 1 \& S4).

Environmental predictors accounted for most of the spatial variance in species turnover, regardless of the spatial grain of the analysis (at $400-\mathrm{km}$ resolution, $R^{2}=0.6237, F_{8,3312}=$ 688.8 ; at $100-\mathrm{km}$ resolution, $R^{2}=0.5745, F_{8,119307}=2.02 \times$ $10^{4}$; see Fig. S5 for additional details). In a bootstrap analysis, 

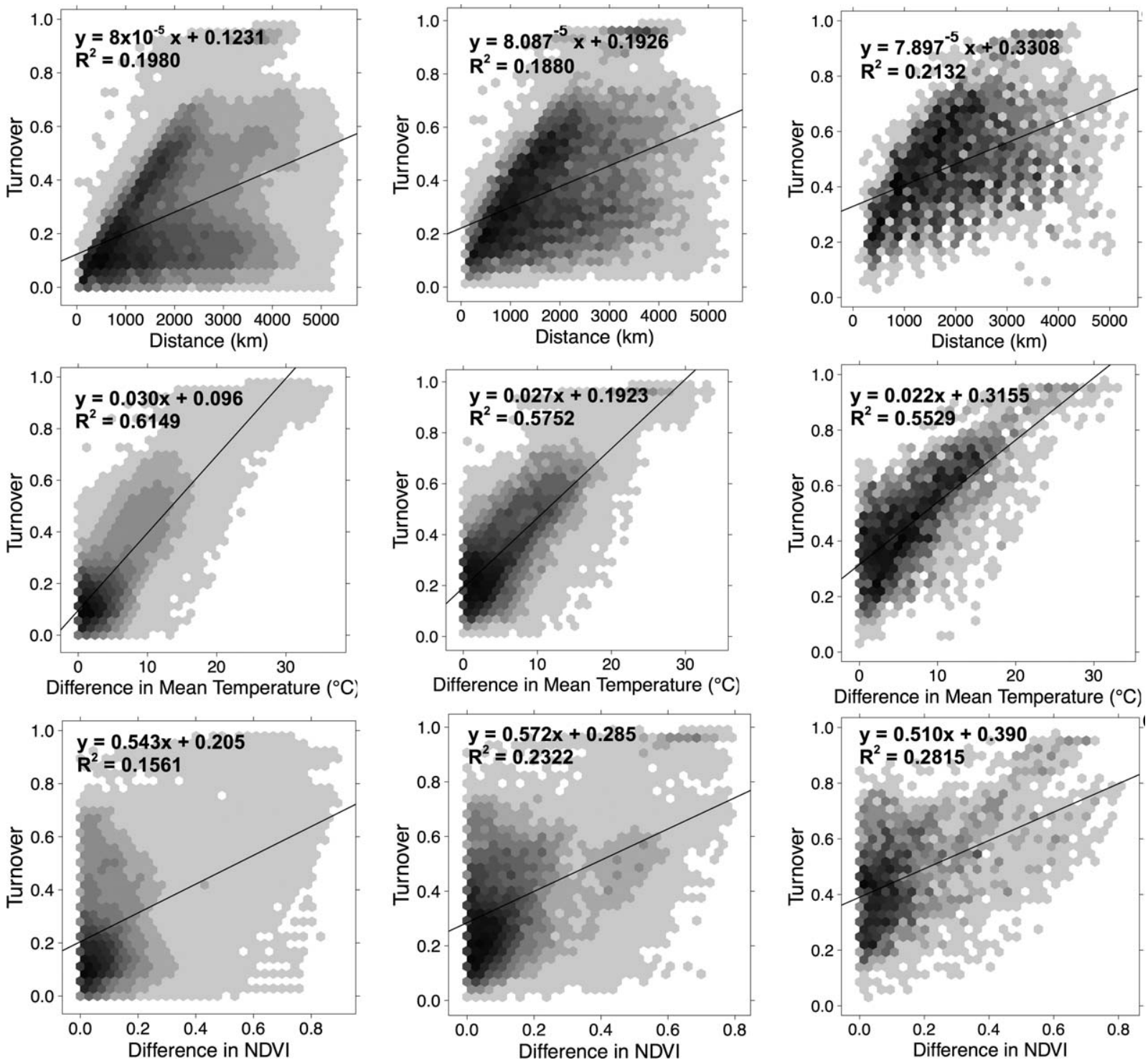

Figure 1 Spatial turnover of species as a function of the geographical and environmental distance between three different quadrat scales (left column, $100 \mathrm{~km} \times 100 \mathrm{~km}$; middle column, $200 \mathrm{~km} \times 200 \mathrm{~km}$; right column, $400 \mathrm{~km} \times 400 \mathrm{~km}$ ). Turnover was measured using the Jaccard index of dissimilarity. NDVI, normalized difference vegetation index. $n=3321,21,946$ and 109,316 pairwise quadrat comparisons for each respective quadrat size.

the principal component of temperature (a synthetic metric that combined mean, minimum and maximum temperature into a single component that accounted for $83.34 \%$ of the variation in the three variables) emerged as the most important predictor of spatial turnover in statistical tests, regardless of the spatial grain of analysis (see Figs $2 \&$ S5). Absolute and average sampling intensity were consistently found to be relatively poor predictors of spatial turnover (see Figs 2 \& S5). We observed similar rankings with the Simpson dissimilarity measure, although the overall fit decreased with this metric (at $100-\mathrm{km}$ resolution, $R^{2}=0.2041, F_{8,119796}=3842$; see Fig. S6).

The highest levels of annual temperature change are observed in northern Canada (Fig. 3), coinciding with the highest levels of species turnover through time (Fig. 4; see Fig. S7 for the distribution of turnover values). There is a significant relationship between the levels of temporal temperature change within a quadrat and the amount of species turnover experienced (see Fig. 5; $R^{2}=0.0593, F_{1,362}=22.83$, $P<0.05$ ), although there is a high level of variance around the mean. Log-transforming both the predictor and the response variable did not improve the coefficient of determination in regression models (see Fig. S8). The mean quadratlevel temporal turnover in $100-\mathrm{km}$ quadrats is 0.7127 $(\mathrm{SE}=0.0105)$. Differences in sampling intensity within a quadrat did not result in higher turnover scores (see Fig. S9). The inclusion of this sampling intensity variable in the linear regression model increased the value of $R^{2}$ to 0.1306 ; however, the difference in temperature remained significantly positively correlated with temporal turnover $\left(F_{2,361}=28.26\right.$, $P<0.05)$. This result remained consistent when three 
Figure 2 A bootstrap analysis of the relative importance of the environmental variables for spatial turnover of species between the $100 \mathrm{~km} \times 100 \mathrm{~km}$ quadrats. Four methods are used: LMG (i.e.

Lindeman, Meranda and Gold), Last (last variable in model), First (first variable in model) and Pratt (see Methods for a description of how they were calculated). Included variables are a principal component of temperature (Temp), distance (Dist), precipitation (Prec), normalized difference vegetation index (NDVI), land use/land cover (LULC), elevation (Elev), average sampling intensity (AveSI), and absolute sampling intensity (SI). Vertical lines on each bar represent 95\% bootstrap confidence intervals for each estimate. $n=109,316$ pairwise quadrat comparisons.
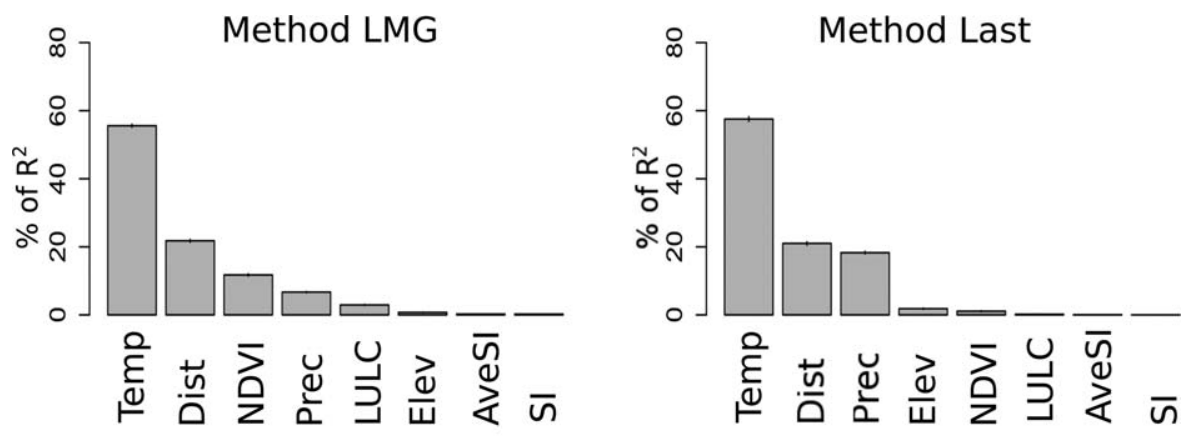

Method First
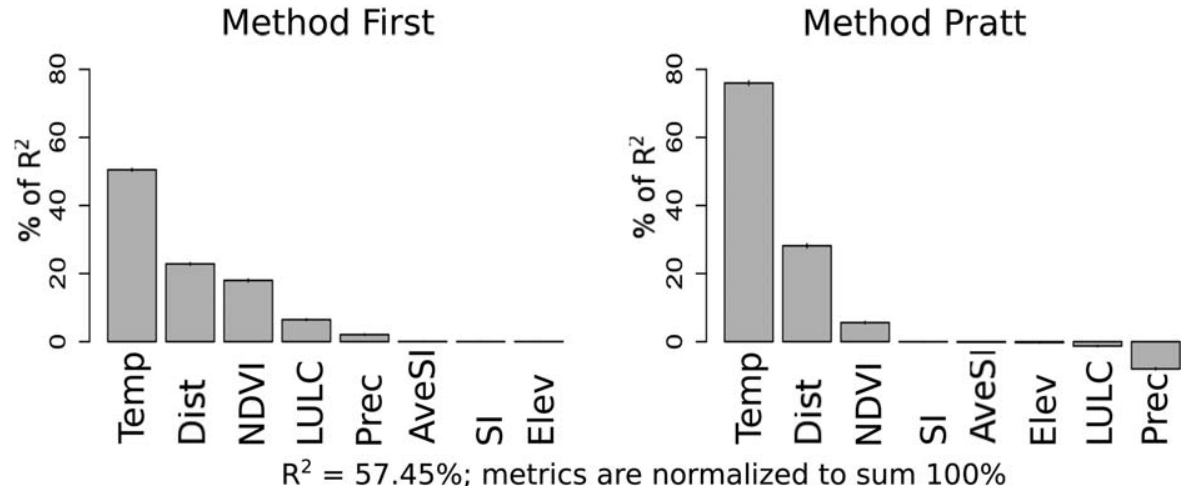

outlying sampling intensity points were excluded $\left(R^{2}=0.1296\right.$, $\left.F_{2,358}=27.8, P<0.05\right)$ and when the effects of two additional sampling intensity metrics (absolute sampling intensity in either time period) were investigated $\left(R^{2}=0.3576\right.$, $F_{3,360}=80.55, P<0.05$ for temperature change and $P<0.05$ and $P=0.3149$ for each respective sampling metric).

The slopes for the temperature variable in both the spatial and the temporal analysis were initially quite different. The slope of the mean temperature variable in the spatial analysis was 0.0299 , with a $95 \%$ confidence interval of $0.0298-0.0301$. The slope of the temperature variable in the temporal analysis was 0.1177 , with a $95 \%$ confidence interval of 0.0692 0.1661 . However, after accounting for sampling intensity in the temporal analysis (difference in absolute sampling intensity between time periods, as well as absolute sampling intensity in both Time 1 and Time 2), the slope is 0.0595 , with a
Figure 3 Quadrat-level mean temperature change $\left({ }^{\circ} \mathrm{C}\right)$ between 1900-1974 and 1985-2010 in selected $100 \mathrm{~km} \times 100 \mathrm{~km}$ quadrats. Only well-sampled quadrats were included. Blank areas indicate omitted grid cells that were not sampled in both time periods. $n=364$ quadrats.

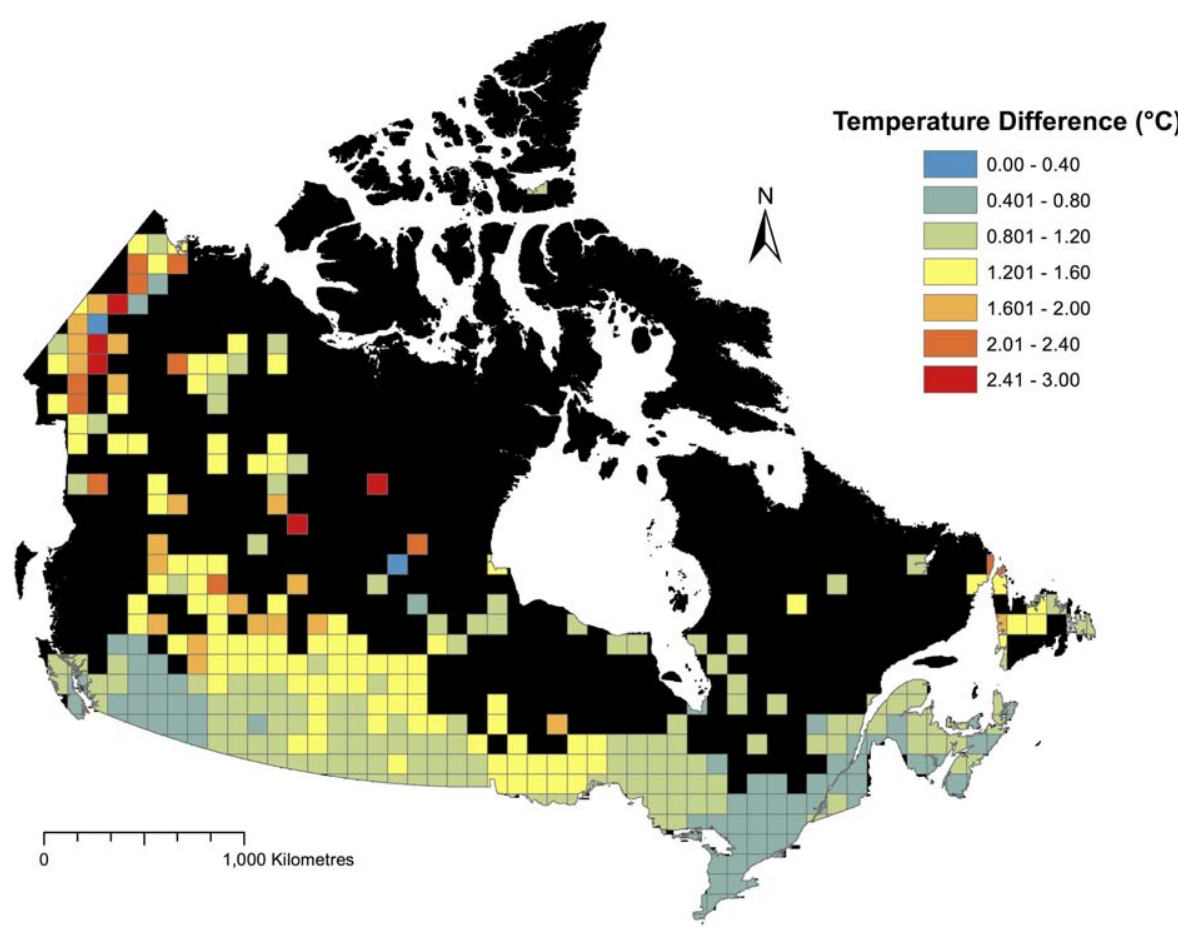




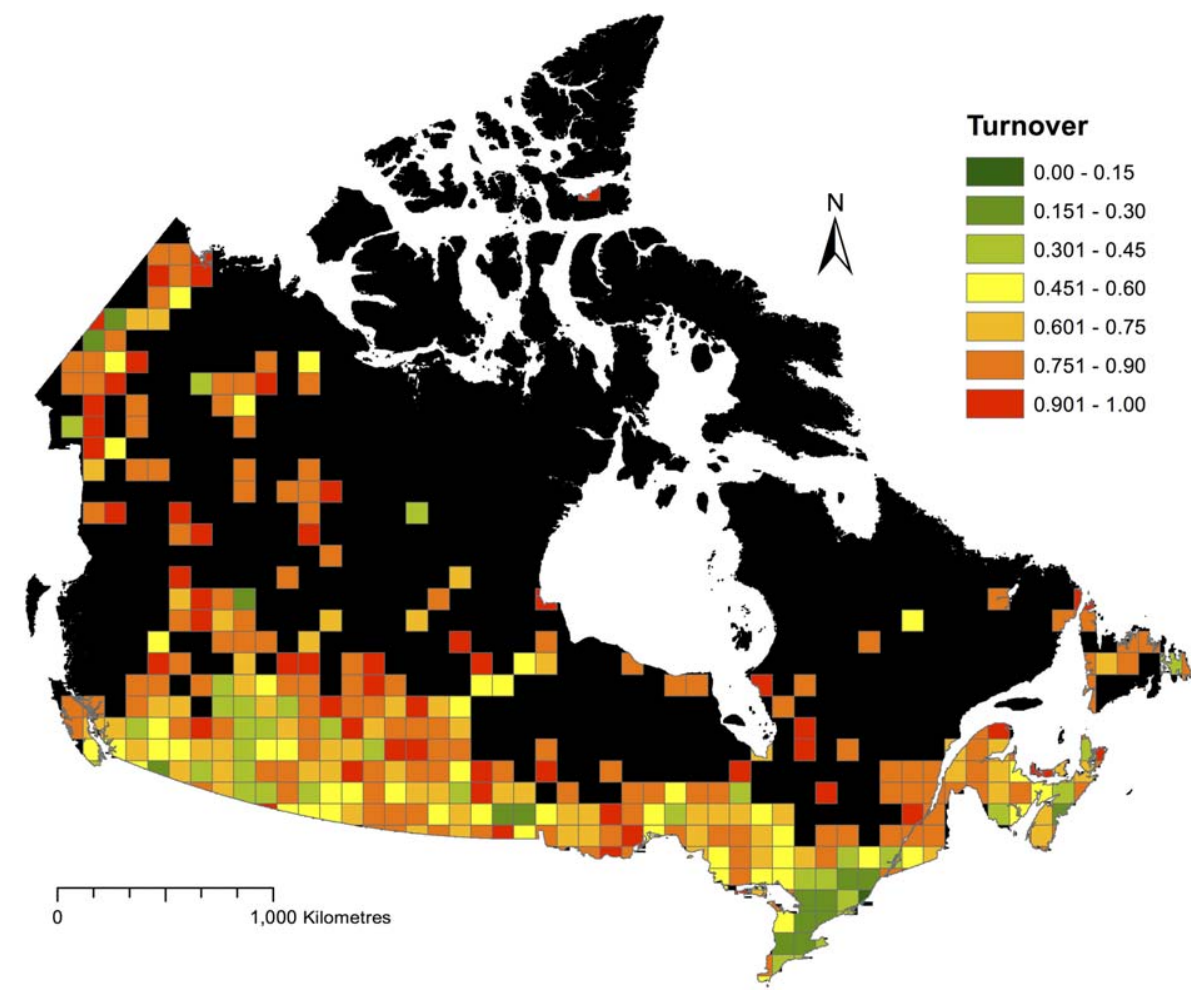

Figure 4 Species turnover measurements within individual $100 \mathrm{~km} \times 100 \mathrm{~km}$ quadrats, between 1900-74 and 1985-2010. Blank areas indicate omitted grid cells that were not sampled in both time periods. $n=364$ quadrats.
95\% confidence interval of 0.0194-0.0995, which directly overlaps with the slope from the spatial temperature analysis.

There is no signficant relationship between absolute precipitation change and temporal turnover $\left(F_{1,362}=2.335\right.$, $P=0.1273$; see Fig. S10). Annual precipitation totals within a quadrat increased by an average of $64 \mathrm{~mm}$ between the two time periods, a $2.92 \%$ increase from Time 1 quadrat averages. Temperature increased within a quadrat by an average of $1.115^{\circ} \mathrm{C}$, a proportional increase of $3.89 \%$ from Time 1

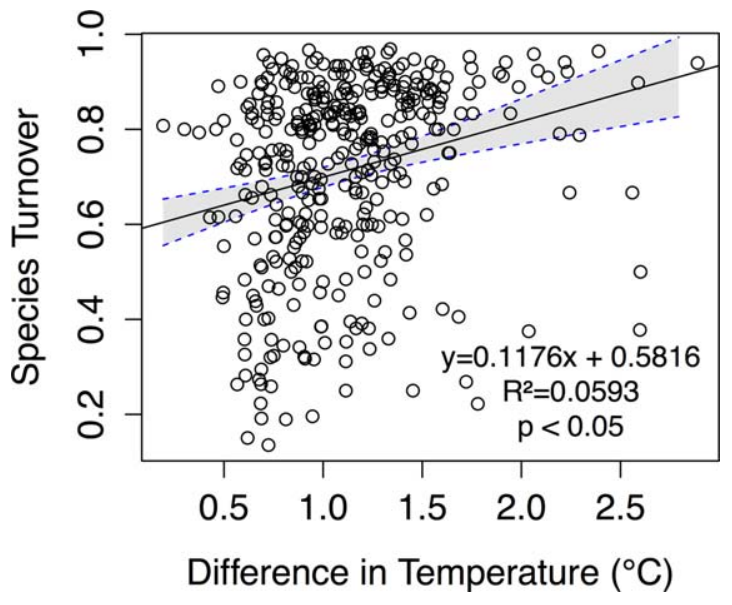

Figure 5 Species turnover as a function of difference in average temperature $\left({ }^{\circ} \mathrm{C}\right)$ between time periods (1900-74 versus 19852010). Hatched lines indicate the $95 \%$ confidence interval. Quadrats were $100 \mathrm{~km} \times 100 \mathrm{~km}$. Turnover was measured using the Jaccard index of dissimilarity. $n=364$ quadrats.

[Color figure can be viewed at wileyonlinelibrary.com] quadrat averages. Additionally, there is no significant relationship between absolute change in NDVI and temporal turnover in a quadrat $\left(F_{1,362}=0.4153, P=0.5197\right.$; see Fig. S11).

Dispersal limitation is predicted to limit a species' ability to adequately respond to climate change (Leroux et al., 2013). We found a strong relationship between observed levels of temporal turnover within a quadrat and what would be predicted under maximum dispersal capabilities (see Fig. 6; $\left.R^{2}=0.5456, P<0.05\right)$, with a RMSE value around the $1: 1$ line of 0.1564 . A map of the residuals from this relationship can be found in Fig. S12.

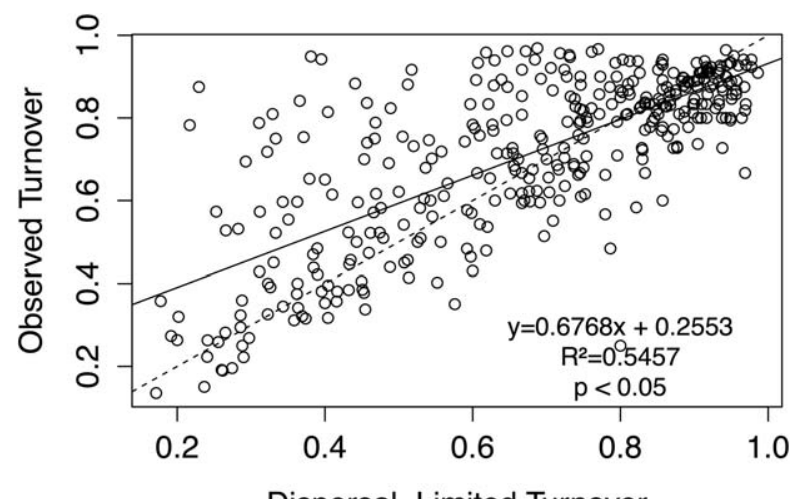

Figure 6 Dispersal-limited turnover versus observed butterfly turnover. Dispersal limitations were constructed using 100-km buffers around 1900-74 records, and turnover was calculated within each $100 \mathrm{~km} \times 100 \mathrm{~km}$ quadrat. The solid line represents the result of a linear regression. The broken line indicates the 1:1 line. $n=354$ quadrats. 


\section{DISCUSSION}

The determinants of variation in species composition have long been debated among ecologists (Hubbell, 2001; Field et al., 2009), not just because these patterns illuminate processes that are vital to ecology and evolutionary biology, but because of their relevance to conservation efforts (Gallagher et al., 2013). Investigating the drivers behind spatial and temporal turnover in species composition is vital to anticipating where species will disperse as environments change and how to manage these effects (Buckley et al., 2013; Robillard et al., 2015). We have compared competing hypotheses that predict dissimilarity across a variety of spatial grains. Although many variables correlate with spatial turnover in communities, temperature outperformed other metrics at all spatial scales. It is important to emphasize that turnover metrics do not measure changing species distributions individually and do not directly measure whether species are tracking their climatic niche. However, the correlation between temperature change and temporal turnover has a strong mechanistic basis for its effects on butterfly distributions.

Spatial relationships observed between temperature and changes in species composition were consistent temporally. In a comparison of early and recent butterfly records, we found that species composition differed significantly within quadrats and that the highest turnover was occurring in quadrats experiencing the greatest temperature change. Communities are not only responding to change, but they are doing so predictably and proportionately to the observed temperature change through time. Quadrats experiencing the highest turnover were often located in the northern regions of Canada, consistent with the pattern of where climate is changing most rapidly (Loarie et al., 2009). Change in precipitation is not a significant predictor of temporal turnover, and precipitation totals have not increased as rapidly as temperature between time periods. These results may inform conservation applications by identifying locations where biotic turnover is most substantial and, consequently, where potential management efforts may be most needed.

Energy-related climatic factors drive diversity patterns through physiological constraints inherent to each species. Niche conservatism, the tendency for an organism to maintain similar environmental limits to their existing range (Wiens \& Graham, 2005), suggests that species will respond to global change by seeking out environmentally similar areas (Bedford et al., 2012). Because butterflies originated under tropical conditions (Hawkins \& DeVries, 2009), any niche conservatism in their tolerance to warm conditions would provide a potential mechanism determining how this group responds to climate change (see Kerr et al., 2015). Although productivity measurements have previously been associated with Canadian butterfly dissimilarity using a small butterfly dataset in a purely spatial analysis of point similarity (Andrew et al., 2012), temperature strongly outperforms other environmental predictors across spatial scales.
Dispersal is a key process that may help species mitigate the impacts of natural and anthropogenic environmental change (Boeye et al., 2013; Dapporto \& Dennis, 2013). Because the pace of recent climate change is high relative to the apparent capacity of most species to evolve new tolerances, dispersal and establishment of populations in historically unoccupied areas are critical determinants of whether species can successfully track shifting climatic conditions (Leroux et al., 2013). We observed a strong association between dispersal patterns predicted by dispersal limitation and actual observations. This could suggest that many quadrats are experiencing levels of turnover that are comparable to those that would be found if species were shifting at their maximum dispersal capabilities. This further emphasizes the need for protected areas that can account for the polewards migration of species over the coming century (Robillard et al., 2015). Alternatively, high levels of turnover could indicate climate-induced local extinctions within communities, and this analysis cannot differentiate between these two responses. However, there are many quadrats that are experiencing lower levels of turnover than predicted under maximum dispersal, and they appear to be spatially clustered. This could reflect quadrat-level dispersal barriers, such as complex topography, intervening habitat that is inappropriate for the species or high levels of human modification of the landscape. Testing for factors that limit dispersal-mediated turnover in the face of rapid climate change is an important future research priority and will be useful for understanding the origins of climate debts in regions undergoing rapid climate change (Devictor et al., 2012).

Sampling intensity varies across the broad areas of North America included in this research. We accounted for potential consequences of sampling variation in several ways. First, we excluded many of the northern quadrats from the analysis. Although the butterfly dataset is spatially biased towards the southern border of Canada, we also tested for the effect of differences in average sampling intensity and found no evidence that it had any influence on spatial turnover: average sampling intensity was consistently less important than temperature-related variables. Although quadrats that were sampled in northern areas include fewer records than southern Canada, it is possible that this primarily reflects lower numbers of repeated observations of the same species (i.e. multiple observations of the same species within a quadrat). Despite this, northern areas need greater future attention with respect to biodiversity monitoring to improve the capacity to predict where changes will occur and to detect changes that are under way.

Although species turnover is generally increasing between the two time periods used in this study and in conjunction with climate change, there is wide variation in this response. Biotic turnover that corresponds with changing temperatures through time may indicate that species are shifting successfully to new areas as climate changes (although this was not explicitly tested in this study), but differences in dispersal rates among species and regions may accelerate biotic 
homogenization. Species with greater dispersal ability or more general host plant requirements, for example, may be more successful in responding to climate change (Leroux et al., 2013), whereas dispersal-limited or specialist species are likely to become rarer. Observed temporal turnover scores may also reflect that some species are not shifting their distributions through time and are instead experiencing local extinction events (which can also increase dissimilarity between quadrats). We are not able to differentiate between individual species in our approach, and so this level of analysis warrants further investigation.

The substantial changes in butterfly species composition across environmental gradients in Canada clearly reflect strong effects of temperature, and rapid warming over recent decades across this enormous region is now contributing to biotic turnover through time as well. Trait-based and environmental limitations on community responses to global change represent an important and emerging frontier for macroecological research and its contributions to our knowledge about global change.

\section{ACKNOWLEDGEMENTS}

This work was made possible by support from the Natural Sciences and Engineering Research Council of Canada (Discovery Grant Program, to J.T.K; Canada Graduate Scholarships - Master's award, to J.M.M.L.). This work was further supported by an Early Researcher Award from the Ontario Ministry of Research and Innovation (J.T.K) and through the University of Ottawa Research Chair in Macroecology and Conservation (J.T.K). D.M.D. was supported by a Distinguished Visiting Scholar grant through the University of Ottawa and a Faculty Professional Development Leave supported by Iowa State University. Many thanks to Maxim Larrivée for guidance and many helpful comments.

\section{REFERENCES}

Algar, A.C., Kharouba, H.M., Young, E.R. \& Kerr, J.T. (2009) Predicting the future of species diversity: macroecological theory, climate change, and direct tests of alternative forecasting methods. Ecography, 32, 22-33.

Algar, A.C., Kerr, J.T. \& Currie, D.J. (2011) Quantifying the importance of regional and local filters for community trait structure in tropical and temperate zones. Ecology, 92, 903-914.

Andrew, M.E., Wulder, M.A., Coops, N.C. \& Baillargeon, G. (2012) Beta-diversity gradients of butterflies along productivity axes. Global Ecology and Biogeography, 21, 352-364.

ArcGIS Desktop (2014) ArcGIS Desktop, release 10.3. Environmental Systems Research Institute, Redlands, CA.

Baselga, A. (2010) Partitioning the turnover and nestedness components of beta diversity. Global Ecology and Biogeography, 19, 134-143.

Baselga, A., Jiménez-Valverde, A. \& Niccolini, G. (2007) A multiple-site similarity measure independent of richness. Biology Letters, 3, 642-645.
Bedford, F.E., Whittaker, R.J. \& Kerr, J.T. (2012) Systemic range shift lags among a pollinator species assemblage following rapid climate change. Botany, 90, 587-597.

Blackburn, T.M. \& Gaston, K.J. (1996) The distribution of bird species in the New World: patterns in species turnover. Oikos, 77, 146-152.

Blois, J.L., Williams, J.W., Fitzpatrick, M.C., Jackson, S.T. \& Ferrier, S. (2013) Space can substitute for time in predicting climate-change effects on biodiversity. Proceedings of the National Academy of Sciences USA, 110, 9374-9379.

Boeye, J., Travis, J.M., Stoks, R. \& Bonte, D. (2013) More rapid climate change promotes evolutionary rescue through selection for increased dispersal distance. Evolutionary Applications, 6, 353-364.

Boucher-Lalonde, V., Morin, A. \& Currie, D.J. (2012) How are tree species distributed in climatic space? A simple and general pattern. Global Ecology and Biogeography, 21, 11571166.

Buckley, L.B. \& Jetz, W. (2008) Linking global turnover of species and environments. Proceedings of the National Academy of Sciences USA, 105, 17836-17841.

Buckley, L.B., Tewksbury, J.J. \& Deutsch, C.A. (2013) Can terrestrial ectotherms escape the heat of climate change by moving? Proceedings of the Royal Society B: Biological Sciences, 280, 20131149.

Carr, D. (2014) hexbin: Hexagonal binning routines. R package version 1.27.0. Available at: http://CRAN.R-project.org/ package $=$ hexbin

Chalcraft, D.R., Williams, J.W., Smith, M.D. \& Willig, M.R. (2004) Scale dependence in the species-richnessproductivity relationship: the role of species turnover. Ecology, 85, 2701-2708.

Chase, J.M. \& Myers, J.A. (2011) Disentangling the importance of ecological niches from stochastic processes across scales. Philosophical Transactions of the Royal Society B: Biological Sciences, 366, 2351-2363.

Chen, I.C., Hill, J.K., Ohlemüller, R., Roy, D.B. \& Thomas, C.D. (2011) Rapid range shifts of species associated with high levels of climate warming. Science, 333, 1024-1026.

Chen, X., Hu, B. \& Yu, R. (2005) Spatial and temporal variation of phenological growing season and climate change impacts in temperate eastern China. Global Change Biology, 11, 1118-1130.

Cihlar, J., Beaubien, J. \& Latifovic, R. (2001) Land cover of Canada 1998. Digital data set documentation. Natural Resources Canada, Ottawa, ON.

Dapporto, L. \& Dennis, R.L. (2013) The generalist-specialist continuum: testing predictions for distribution and trends in British butterflies. Biological Conservation, 157, 229-236.

Darlington, R.B. (1968) Multiple regression in psychological research and practice. Psychological Bulletin, 69, 161.

Devictor, V., van Swaay, C., Brereton, T. et al. (2012) Differences in the climatic debts of birds and butterflies at a continental scale. Nature Climate Change, 2, 121-124.

Dobrovolski, R., Melo, A.S., Cassemiro, F.A. \& Diniz-Filho, J.A.F. (2012) Climatic history and dispersal ability explain 
the relative importance of turnover and nestedness components of beta diversity. Global Ecology and Biogeography, 21, 191-197.

Dormann, C.F., McPherson, J.M., Araújo, M.B., Bivand, R., Bollinger, J., Carl, G., Davies, R.G., Hirzel, A., Jetz, W., Kissling, W.D., Kühn, I., Ohlemüller, R., Peres-Neto, P.R., Reineking, B., Schröder, B., Schurr, F.M. \& Wilson, R. (2007) Methods to account for spatial autocorrelation in the analysis of species distributional data: a review. Ecography, 30, 609-628.

Elith, J. \& Leathwick, J.R. (2009) Species distribution models: ecological explanation and prediction across space and time. Annual Review of Ecology, Evolution, and Systematics, 40, 677-697.

Eskildsen, A., Roux, P.C., Heikkinen, R.K., Høye, T.T., Kissling, W.D., Pöyry, J., Wisz, M.S. \& Luoto, M. (2013) Testing species distribution models across space and time: high latitude butterflies and recent warming. Global Ecology and Biogeography, 22, 1293-1303.

Evans, K.L., Jackson, S.F., Greenwood, J.J. \& Gaston, K.J. (2006) Species traits and the form of individual speciesenergy relationships. Proceedings of the Royal Society B: Biological Sciences, 273, 1779-1787.

Ferrier, S. \& Guisan, A. (2006) Spatial modelling of biodiversity at the community level. Journal of Applied Ecology, 43, 393-404.

Field, R., Hawkins, B.A., Cornell, H.V., Currie, D.J., DinizFilho, J.A.F., Guégan, J.F., Kaufman, D.M., Kerr, J.T., Mittelbach, G.G., Oberdorff, T., O’Brien, E.M. \& Turner, J.R.G. (2009) Spatial species-richness gradients across scales: a meta-analysis. Journal of Biogeography, 36, 132-147.

Gallagher, R.V., Hughes, L. \& Leishman, M.R. (2013) Species loss and gain in communities under future climate change: consequences for functional diversity. Ecography, 36, 531540.

Gaston, K.J., Davies, R.G., Orme, C.D.L., Olson, V.A., Thomas, G.H., Ding, T.S., Rasmussen, P.C., Lennon, J.J., Bennett, P.M., Owens, I.P.F. \& Blackburn, T.M. (2007) Spatial turnover in the global avifauna. Proceedings of the Royal Society B: Biological Sciences, 274, 1567-1574.

Goetz, S.J., Bunn, A.G., Fiske, G.J. \& Houghton, R.A. (2005) Satellite-observed photosynthetic trends across boreal North America associated with climate and fire disturbance. Proceedings of the National Academy of Sciences USA, 102, 13521-13525.

Goward, S.N., Markham, B., Dye, D.G., Dulaney, W. \& Yang, J. (1991) Normalized difference vegetation index measurements from the advanced very high resolution radiometer. Remote Sensing of Environment, 35, 257-277.

Grömping, U. (2006) Relative importance for linear regression in R: the package relaimpo. Journal of Statistical Software, $17,1-27$.

Hawkins, B.A. \& DeVries, P.J. (2009) Tropical niche conservatism and the species richness gradient of North American butterflies. Journal of Biogeography, 36, 1698-1711.
Hillebrand, H., Soininen, J. \& Snoeijs, P. (2010) Warming leads to higher species turnover in a coastal ecosystem. Global Change Biology, 16, 1181-1193.

Hubbell, S.P. (2001) The unified neutral theory of biodiversity and biogeography. Princeton University Press, Princeton, NJ.

Jackson, S.T., Betancourt, J.L., Booth, R.K. \& Gray, S.T. (2009) Ecology and the ratchet of events: climate variability, niche dimensions, and species distributions. Proceedings of the National Academy of Sciences USA, 106, 1968519692.

Jurasinski, G., Retzer, V. \& Beierkuhnlein, C. (2009) Inventory, differentiation, and proportional diversity: a consistent terminology for quantifying species diversity. Oecologia, 159, 15-26.

Keil, P., Schweiger, O., Kühn, I., Kunin, W.E., Kuussaari, M., Settele, J., Henle, K., Kunin, W.E., Pe'er, G., Lengyel, S., Moustakas, A., Steinicke, H. \& Storch, D. (2012) Patterns of beta diversity in Europe: the role of climate, land cover and distance across scales. Journal of Biogeography, 39, 1473-1486.

Kerr, J.T. \& Cihlar, J. (2003) Land use and land use intensity estimation in Canada from SPOT4/VEGETATION and ancillary data. Global Ecology and Biogeography, 12, 161172.

Kerr, J.T. \& Ostrovsky, M. (2003) From space to species: ecological applications for remote sensing. Trends in Ecology and Evolution, 18, 299-305.

Kerr, J.T., Southwood, T.R.E. \& Cihlar, J. (2001) Remotely sensed habitat diversity predicts butterfly species richness and community similarity in Canada. Proceedings of the National Academy of Sciences USA, 98, 11365-11370.

Kerr, J.T., Kharouba, H.M. \& Currie, D.J. (2007) The macroecological contribution to global change solutions. Science, 316, 1581-1584.

Kerr, J.T., Pindar, A., Galpern, P., Packer, L., Potts, S.G., Roberts, S.M., Rasmont, P., Schweifer, O., Colla, S.R., Richardson, L.L., Wagner, D.L., Gall, L.F., Sikes, D.S. \& Pantoja, A. (2015) Climate change impacts on bumblebees converge across continents. Science, 349, 177-180.

Kharouba, H.M., Algar, A.C. \& Kerr, J.T. (2009) Historically calibrated predictions of butterfly species' range shift using global change as a pseudo-experiment. Ecology, 90, 22132222.

Koleff, P., Gaston, K.J. \& Lennon, J.J. (2003) Measuring beta diversity for presence-absence data. Journal of Animal Ecology, 72, 367-382.

Kraft, N.J., Comita, L.S., Chase, J.M., Sanders, N.J., Swenson, N.G., Crist, T.O., Stegen, J.C., Velland, M., Boyle, B., Anderson, M.J., Cornell, H.V., Davies, K.F., Freestone, A.L., Inouye, B.D., Harrison, S.P. \& Myers, J.A. (2011) Disentangling the drivers of $\beta$ diversity along latitudinal and elevational gradients. Science, 333, 1755-1758.

Larrivée, M., Prudic, K.L., McFarland, K. \& Kerr, J.T. (2014) eButterfly: a citizen-based butterfly database in the biological sciences. Available at: http://www.e-butterfly.org 
Legendre, P. \& De Cáceres, M. (2013) Beta diversity as the variance of community data: dissimilarity coefficients and partitioning. Ecology Letters, 16, 951-963.

Lennon, J.J., Koleff, P., Greenwood, J.J.D. \& Gaston, K.J. (2001) The geographical structure of British bird distributions: diversity, spatial turnover and scale. Journal of Animal Ecology, 70, 966-979.

Leroux, S.J., Larrivée, M., Boucher-Lalonde, V., Hurford, A., Zuloaga, J., Kerr, J.T. \& Lutscher, F. (2013) Mechanistic models for the spatial spread of species under climate change. Ecological Applications, 23, 815-828.

Lindeman, R.H., Merenda, P.F. \& Gold, R.Z. (1980) Introduction to bivariate and multivariate analysis. Scott Foresman \& Co., Glenview, IL.

Liu, J., Chen, J.M., Cihlar, J. \& Park, W.M. (1997) A processbased boreal ecosystem productivity simulator using remote sensing inputs. Remote Sensing of Environment, 62, 158-175.

Loarie, S.R., Duffy, P.B., Hamilton, H., Asner, G.P., Field, C.B. \& Ackerly, D.D. (2009) The velocity of climate change. Nature, 462, 1052-1055.

McKenney, D.W., Hutchinson, M.F., Papadopol, P., Lawrence, K., Pedlar, J., Campbell, K., Milewska, E., Hopkinson, R.F., Price, D. \& Owen, T. (2011) Customized spatial climate models for North America. Bulletin of the American Meteorological Society, 92, 1611-1622.

McKnight, M.W., White, P.S., McDonald, R.I., Lamoreux, J.F., Sechrest, W., Ridgely, R.S. \& Stuart, S.N. (2007) Putting beta-diversity on the map: broad-scale congruence and coincidence in the extremes. PLoS Biology, 5, e272.

Meynard, C.N., Devictor, V., Mouillot, D., Thuiller, W., Jiguet, F. \& Mouquet, N. (2011) Beyond taxonomic diversity patterns: how do $\alpha, \beta$ and $\gamma$ components of bird functional and phylogenetic diversity respond to environmental gradients across France? Global Ecology and Biogeography, 20, 893-903.

Myneni, R.R., Keeling, C.D., Tucker, C.J., Asrar, G. \& Nemani, R.R. (1997) Increased activity on northern vegetation inferred from satellite-based vegetation index, atmospheric carbon dioxide, and temperature data. Nature, 386, 698-702.

Nekola, J.C. \& White, P.S. (1999) The distance decay of similarity in biogeography and ecology. Journal of Biogeography, 26, 867-878.

Oksanen, J., Blanchet, F.G., Kindt, R., Legendre, P., Minchin, P.R., O'hara, R.B., Simpson, G.L. \& Solymos, P. (2015) vegan: Community ecology package. $\mathrm{R}$ package version 2.21. Available at: http://CRAN.R-project.org/package=vegan

Parmesan, C. (2006) Ecological and evolutionary responses to recent climate change. Annual Review of Ecology, Evolution, and Systematics, 37, 637-669.

Pellissier, L., Alvarez, N., Espíndola, A., Pottier, J., Dubuis, A., Pradervand, J.N. \& Guisan, A. (2013) Phylogenetic alpha and beta diversities of butterfly communities correlate with climate in the western Swiss Alps. Ecography, 36, 541-550.
Pettorelli, N. (2013) The normalized difference vegetation index. Oxford University Press, Oxford.

Pettorelli, N., Vik, J.O., Mysterud, A., Gaillard, J.M., Tucker, C.J. \& Stenseth, N.C. (2005) Using the satellite-derived NDVI to assess ecological responses to environmental change. Trends in Ecology and Evolution, 20, 503-510.

Pinzon, J.E. \& Tucker, C.J. (2014) A non-stationary 19812012 AVHRR NDVI3g time series. Remote Sensing, 6, 6929-6960.

Pratt, J.W. 1987 Dividing the indivisible: using simple symmetry to partition variance explained. In Proceedings of second international conference in statistics (ed. by T. Pukkila and S. Puntanen), pp. 245-260. University of Tampere, Tampere, Finland.

Qian, H. \& Ricklefs, R.E. (2007) A latitudinal gradient in large-scale beta diversity for vascular plants in North America. Ecology Letters, 10, 737-744.

Qian, H. \& Ricklefs, R.E. (2012) Disentangling the effects of geographic distance and environmental dissimilarity on global patterns of species turnover. Global Ecology and Biogeography, 21, 341-351.

R Development Core Team. (2013) R: A language and environment for statistical computing. R Foundation for Statistical Computing, Vienna, Austria. Available at: http://www. R-project.org/

Robillard, C., Coristine, L., Soares, R. \& Kerr, J.T. (2015) Facilitating climate change-induced range shifts through a continental land use barrier. Conservation Biology, 29, 1586-1595.

Soininen, J. (2010) Species turnover along abiotic and biotic gradients: patterns in space equal patterns in time? BioScience, 60, 433-439.

Statistics Canada (1996) Census of agriculture. Government of Canada, Ottawa.

Stegen, J.C., Freestone, A.L., Crist, T.O., Anderson, M.J., Chase, J.M., Comita, L.S., Cornell, H.V., Davies, K.F., Harrison, S.P., Hurlbert, A.H., Inouye, B.D., Kraft, N.J.B., Myers, J.A., Sanders, N.J., Swenson, N.G. \& Velland, M. (2013) Stochastic and deterministic drivers of spatial and temporal turnover in breeding bird communities. Global Ecology and Biogeography, 22, 202-212.

Tuomisto, H. \& Ruokolainen, K. (2006) Analyzing or explaining beta diversity? Understanding the targets of different methods of analysis. Ecology, 87, 2697-2708.

Tylianakis, J.M., Didham, R.K., Bascompte, J. \& Wardle, D.A. (2008) Global change and species interactions in terrestrial ecosystems. Ecology Letters, 11, 1351-1363.

Ulrich, W. \& Gotelli, N.J. (2007) Disentangling community patterns of nestedness and species co-occurrence. Oikos, 116, 2053-2061.

Veech, J.A. \& Crist, T.O. (2007) Habitat and climate heterogeneity maintain beta-diversity of birds among landscapes within ecoregions. Global Ecology and Biogeography, 16, 650-656.

Veloz, S.D., Williams, J.W., Blois, J.L., He, F., Otto-Bliesner, B. \& Liu, Z. (2012) No-analog climates and shifting 
realized niches during the late quaternary: implications for 21st-century predictions by species distribution models. Global Change Biology, 18, 1698-1713.

Whittaker, R.H. (1972) Evolution and measurement of species diversity. Taxon, 213-251.

Wiens, J.A., Stralberg, D., Jongsomjit, D., Howell, C.A. \& Snyder, M.A. (2009) Niches, models, and climate change: assessing the assumptions and uncertainties. Proceedings of the National Academy of Sciences USA, 106,19729-19736.

Wiens, J.J. \& Graham, C.H. (2005) Niche conservatism: integrating evolution, ecology, and conservation biology. Annual Review of Ecology, Evolution, and Systematics, 519539.

\section{SUPPORTING INFORMATION}

Additional supporting information may be found in the online version of this article at the publisher's web-site:

Figure S1 Histogram of the number of Canadian butterfly observation records between 1900-74 and 1985-2010.

Figure S2 Diagnostic plots for the multivariate linear regression of spatial turnover as a function of environmental distance (400 km $\times 400 \mathrm{~km}$ quadrat scale).

Figure S3 Histogram of residuals obtained from the multiple linear regression of spatial turnover as a function of environmental distance (400 km $\times 400 \mathrm{~km}$ quadrat scale).

Figure S4 Community dissimilarity (or turnover) as a function of environmental distance between three different quadrat scales $(100 \mathrm{~km} \times 100 \mathrm{~km}, 200 \mathrm{~km} \times 200 \mathrm{~km}$ and $400 \mathrm{~km} \times 400 \mathrm{~km})$.

Figure S5 A bootstrap analysis of relative importance of the environmental variables for species turnover in the $400 \mathrm{~km}$ $\times 400 \mathrm{~km}$ quadrats.

Figure S6 A bootstrap analysis of relative importance of the environmental variables for species turnover (measured as the Simpson index of dissimilarity) in the $200 \mathrm{~km} \times 200 \mathrm{~km}$ quadrats.

Figure S7 Distribution of temporal community turnover (measured as the Jaccard index of dissimilarity) values, between $1900-74$ and $1985-2010$ for $100 \mathrm{~km} \times 100 \mathrm{~km}$ grid cells.

Figure $58 \ln$ (Species turnover) as a function of $\ln$ (difference in average temperature, in ${ }^{\circ} \mathrm{C}$ ) between time periods in $100 \mathrm{~km} \times 100 \mathrm{~km}$ quadrats.

Figure S9 Relationship between levels of observed temporal turnover within a quadrat and difference in sampling intensity (measured as the total number of observation records) between the two periods.

Figure S10 Species turnover as a function of difference in average precipitation $(\mathrm{mm})$ between time periods in $100 \mathrm{~km}$ $\times 100 \mathrm{~km}$ quadrats.

Figure S11 Species turnover as a function of difference in normalized difference vegetation index between time periods (1981-84 versus 1985-2010). Quadrats were $100 \mathrm{~km} \times$ $100 \mathrm{~km}$.

Figure S12 Map of the residuals obtained from the linear regression between theoretical dispersal-limited turnover versus observed butterfly turnover.

Table S1 Land-use/land-cover classifications used in the spatial analysis of species turnover.

Table S2 Results of the multiple regression model as well as the bootstrap analysis for the $400 \mathrm{~km} \times 400 \mathrm{~km}$ grid cells.

Table S3 Results of the multiple regression model as well as the bootstrap analysis for the $100 \mathrm{~km} \times 100 \mathrm{~km}$ grid cells.

\section{BIOSKETCHES}

Jayme Lewthwaite is a doctoral candidate at Simon Fraser University who has always been intrigued by what dictates species' range boundaries. She also loves chasing butterflies in her spare time.

Diane Debinski is a conservation biologist who studies butterflies in tallgrass prairie and montane meadow ecosystems. She is particularly interested in questions focused on species rarity, habitat restoration, and the effects of environmental gradients on species distribution patterns.

Jeremy Kerr is Professor of Biology and University Research Chair in Macroecology and Conservation at the University of Ottawa. His research focuses on understanding and predicting how species and ecosystems respond to global change, with an eye to improving their conservation prospects. He is the President of the Canadian Society for Ecology and Evolution and co-founder of the citizen science programs e-Butterfly and BumblebeeWatch. His contribution to this work is dedicated to Evan and Elise, who should inherit their world undiminished.

Editor: Adriana Ruggiero 